\title{
Significant inverse associations of serum $n-6$ fatty acids with plasma plasminogen activator inhibitor-1
}

\author{
Sunghee Lee ${ }^{1}$, J. David Curb ${ }^{2,3,4}$, Takashi Kadowaki ${ }^{2}$, Rhobert W. Evans ${ }^{1}$, Katsuyuki Miura ${ }^{2}$, \\ Tomoko Takamiya $^{1}$, Chol Shin ${ }^{5}$, Aiman El-Saed ${ }^{1}$, Jina Choo ${ }^{6}$, Akira Fujiyoshi ${ }^{2}$, Teruo Otake ${ }^{1}$, \\ Sayaka Kadowaki ${ }^{2}$, Todd Seto ${ }^{3}$, Kamal Masaki ${ }^{3}$, Daniel Edmundowicz ${ }^{7}$, Hirotsugu Ueshima ${ }^{2}$, \\ Lewis H. Kuller ${ }^{1}$ and Akira Sekikawa ${ }^{1,2 *}$ \\ ${ }^{1}$ Department of Epidemiology, Graduate School of Public Health, University of Pittsburgh, Pittsburgh, PA 15213, USA \\ ${ }^{2}$ Department of Health Science, Shiga University of Medical Science, Otsu, Shiga, Japan \\ ${ }^{3} J o h n$ A. Burns School of Medicine, University of Hawaii, Honolulu, HI, USA \\ ${ }^{4}$ Pacific Health Research Institute, Honolulu, HI, USA \\ ${ }^{5}$ Department of Internal Medicine, Ansan Hospital, Korea University, Ansan, South Korea \\ ${ }^{6}$ College of Nursing, Korea University, Seoul, South Korea \\ ${ }^{7}$ Cardiovascular Institute, University of Pittsburgh Medical Center, Pittsburgh, PA, USA
}

(Received 26 January 2011 - Revised 27 April 2011 - Accepted 9 May 2011 - First published online 16 August 2011)

\section{Abstract}

Epidemiological studies suggested that $n-6$ fatty acids, especially linoleic acid (LA), have beneficial effects on CHD, whereas some in vitro studies have suggested that $n-6$ fatty acids, specifically arachidonic acid (AA), may have harmful effects. We examined the association of serum n-6 fatty acids with plasminogen activator inhibitor-1 (PAI-1). A population-based cross-sectional study recruited 926 randomly selected men aged 40-49 years without CVD during 2002-2006 (310 Caucasian, 313 Japanese and 303 Japanese-American men). Plasma PAI-1 was analysed in free form, both active and latent. Serum fatty acids were measured with gas-capillary liquid chromatography. To examine the association between total $n-6$ fatty acids (including LA and AA) and PAI- 1 , multivariate regression models were used. After adjusting for confounders, total $n-6$ fatty acids, LA and AA, were inversely and significantly associated with PAI- 1 levels. These associations were consistent across three populations. Among 915 middle-aged men, serum $n$ - 6 fatty acids had significant inverse associations with PAI-1.

\section{Key words: Plasminogen activator inhibitor-1: Linoleic acid: Fatty acids}

Plasminogen activator inhibitor-1 (PAI-1), a primary inhibitor of plasminogen activators, has an anti-fibrinolytic function ${ }^{(1)}$. High levels of PAI-1 are associated with an increased risk for developing CHD or stroke $\mathrm{e}^{(2-4)}$. This increased risk of CHD may be due to promoting platelet adhesion and acute thrombus formation ${ }^{(4)}$.

Epidemiological studies suggest that linoleic acid (LA), a major component of $n-6$ fatty acids, has beneficial effects on both CHD and its risk factors, whereas some in vitro studies suggest that another $n-6$ fatty acid, arachidonic acid (AA), may have adverse effects. The Nurses' Health Study showed that a high dietary intake of LA has a strong inverse association with $\mathrm{CHD}^{(5)}$. Additionally, a recent meta-analysis found that dietary intake of LA had a strong inverse association with non-fatal cardiovascular events ${ }^{(6)}$. The cardioprotective benefits $^{(7)}$ of $n-6$ fatty acids may be due to decreasing blood pressure $^{(8)}$, reducing thrombosis ${ }^{(9)}$ and improving insulin sensitivity ${ }^{(10)}$. In contrast, several eicosanoids derived from AA are pro-inflammatory and pro-thrombotic, promoting vasoconstriction and enhancing platelet aggregation. Thus, AA has been postulated to adversely affect CHD. However, recent studies have identified AA-derived eicosanoids to have several beneficial attributes including vasodilation, platelet aggregation inhibition and anti-inflammatory effects ${ }^{(11)}$. Interestingly, a recent meta-analysis showed that AA was not associated with fatal or non-fatal cardiovascular events ${ }^{(6)}$.

Abbreviations: AA, arachidonic acid; ERA-JUMP, Electron Beam Tomography, Risk Factor Assessment among Japanese and US Men in the Post-World War II Birth Cohort; LA, linoleic acid; PAI-1, plasminogen activator inhibitor-1.

*Corresponding author: Dr A. Sekikawa, fax +1 412383 1956, email akira@pitt.edu 
These contradictory findings suggest that dietary or serum levels of AA have little association with CHD risk, possibly because AA levels are tightly regulated in the human body ${ }^{(12-14)}$. Although PAI-1 is known to be involved in developing atherothrombosis ${ }^{(15,16)}$, very few studies have reported their associations with $n-6$ fatty acids.

The purpose of the present study was to test whether higher levels of serum $n-6$ fatty acids are associated with lower levels of PAI-1 in men aged 40-49 years. Additionally, we investigated whether higher levels of specific n-6 fatty acids, i.e. LA and AA, are associated with lower levels of PAI-1. To test these hypotheses, we examined data from a population-based cross-sectional study of 926 Caucasian, Japanese and Japanese-American men aged 40-49 years in the Electron Beam Tomography, Risk Factor Assessment among Japanese and US Men in the Post-World War II Birth Cohort (ERA-JUMP) study ${ }^{(17)}$.

\section{Methods}

\section{Study population}

The participants were a randomly selected population-based sample of 926 men aged 40-49 years between 2002 and 2006 from three centres: 310 Caucasian men from Allegheny County, Pennsylvania; 313 Japanese men from Kusatsu, Shiga, Japan; 303 Japanese-American men from Honolulu, Hawaii. Those with clinical CVD or other severe diseases were excluded. Detailed descriptions of the study population have been published previously ${ }^{(17-19)}$. Our final sample was 915 men (304 Caucasian, 313 Japanese and 298 JapaneseAmerican men) due to eleven missing data. Informed consent from each participant was obtained. The protocol for the study was approved by the Institutional Review Boards of the University of Pittsburgh (Pittsburgh, PA, USA), Shiga University of Medical Science (Otsu, Japan) and the Kuakini Medical Center (Honolulu, HI, USA).

Venepuncture was performed in all participants in the early morning after a $12 \mathrm{~h}$ fast, as described previously ${ }^{(17)}$. Fasting serum and plasma samples were stored at $-80^{\circ} \mathrm{C}$, and shipped on dry ice to the Heinz Laboratory at the University of Pittsburgh, to examine the levels of LDL-cholesterol, HDLcholesterol, total cholesterol, TAG, insulin and glucose, as published elsewhere ${ }^{(17)}$. A calorimetric competitive ELISA was utilised to assess C-reactive protein. Hypertension was defined as systolic blood pressure $\geq 140 \mathrm{mmHg}$, diastolic blood pressure $\geq 90 \mathrm{mmHg}$ or anti-hypertensive medication usage. Diabetes mellitus was defined as fasting glucose level $\geq 7 \mathrm{mmol} / \mathrm{l}(1260 \mathrm{mg} / \mathrm{l})$ or anti-diabetic medication usage. 'Alcohol drinker' was defined as a man who drinks alcohol $2 \mathrm{~d}$ or more/week. 'Current smoking' was defined as a man who smoked during the previous month.

\section{Measurement of plasminogen activator inhibitor-1}

As reported previously ${ }^{(20,21)}$, plasma PAI-1 was measured at the clinical biochemistry research laboratory of the University of Vermont (Burlington, VT, USA). Briefly, plasma PAI-1 levels were analysed in citrated plasma ${ }^{(20)}$ by a two-site ELISA, which was sensitive to the free PAI-1 form but not to complexes between tissue plasminogen activator and PAI-1 ${ }^{(21)}$, which was developed by Dr Collen and colleagues ${ }^{(22)}$. The inter-assay CV for PAI-1 was $7 \cdot 7 \%$.

\section{Measurements of serum fatty acids}

To measure serum fatty acids in a percentage of total fatty acid amounts, gas-capillary liquid chromatography (PerkinElmer Clarus 500; PerkinElmer, Waltham, MA, USA) was performed $^{(23)}$. The intra-assay $\mathrm{CV}$ of LA $(18: 2 n-6)$ and AA (20:4n-6) in serum $n-6$ fatty acids were 1.6 and $2 \cdot 8 \%$, respectively $^{(23)}$. The $\mathrm{CV}$ for other fatty acids ranged from 2.5 to $9 \cdot 8 \%{ }^{(23)}$.

\section{Statistical analyses}

Log-transformed PAI-1 was used for the analyses, because the distribution of PAI-1 was skewed. To compare descriptive distributions across centres, an ANOVA for a continuous variable and the Mantel-Haenszel test for a categorical variable were performed. When a significant difference among the three groups existed, we examined multiple comparison tests using Bonferroni's test. To pool the data, we tested interactions according to the centres on associations of PAI-1 with LA as well as with AA. We also assessed the centrespecific associations of $n-6$ fatty acids on PAI- 1 according to the three study centres (Table 3 ). After confirming no interaction and the same direction of the associations by centres, we pooled the data. To estimate the association between serum n-6 fatty acids and PAI-1 levels, we performed multivariate linear regression analyses, adjusting for covariates as follows: in model I, we adjusted for age and centre; in model II, we further adjusted for BMI, current smoking, alcohol drinking, hypertension and diabetes; in model III, we further adjusted for LDL-cholesterol, HDL-cholesterol, TAG and C-reactive protein; in model IV, we further adjusted for marine $n-3$ and trans-fatty acids. Because some eicosanoids of $n-3$ fatty acids were reported to inhibit the production of AA-derived eicosanoids ${ }^{(11)}$, we tested marine $n-3$ as well as trans-fatty acids as covariates. The level of significance was considered to be $P<0.05$. All reported $P$ values were based on two-sided tests. All statistical analyses were performed using SAS 9.2 for Windows (SAS Institute, Inc., Cary, NC, USA).

\section{Results}

The general characteristics of the 915 study participants are shown in Table 1 . The average age of the study participants was 45 years. In the total study population, there were 24.9 and $7 \cdot 5 \%$ participants with hypertension and diabetes, respectively. The median level (interquartile range) of PAI-1 was $37 \cdot 4(23 \cdot 3-58 \cdot 4) \mathrm{ng} / \mathrm{ml}$.

Serum proportions of fatty acids are listed in Table 2. Total $n-6$, total $n-3$, SFA and MUFA made up 39.0, $6 \cdot 5,31 \cdot 2$ and $20.4 \%$, respectively. LA and AA were 28.8 and $8.1 \%$, 
Table 1. General characteristics of the study participants*

(Means or medians with interquartile ranges)

\begin{tabular}{|c|c|c|c|c|}
\hline & $\begin{array}{l}\text { Total } \\
(n 915)\end{array}$ & $\begin{array}{l}\text { Caucasian } \\
\text { men }(n \text { 304) }\end{array}$ & $\begin{array}{l}\text { Japanese } \\
\text { men }(n \text { 313) }\end{array}$ & $\begin{array}{c}\text { Japanese-American } \\
\text { men }(n \text { 298) }\end{array}$ \\
\hline Age (years) & $45 \cdot 4$ & $45 \cdot 0$ & $45 \cdot 1 \dagger$ & $46 \cdot 1 \ddagger$ \\
\hline BMI $\left(\mathrm{kg} / \mathrm{m}^{2}\right)$ & $26 \cdot 5$ & $27 \cdot 9 \S$ & $23 \cdot 7 \dagger$ & $28 \cdot 0$ \\
\hline Waist circumference (cm) & $92 \cdot 6$ & $98 \cdot 7 \S$ & $85 \cdot 2 \dagger$ & $94 \cdot 0 \ddagger$ \\
\hline Systolic blood pressure (mmHg) & $125 \cdot 1$ & $122 \cdot 6$ & $125 \cdot 0$ & $127 \cdot 6 \ddagger$ \\
\hline Diastolic blood pressure (mmHg) & $75 \cdot 8$ & $73 \cdot 1 \S$ & $76 \cdot 5$ & $77 \cdot 7 \ddagger$ \\
\hline Hypertension (\%) & 24.9 & $15 \cdot 1 \S$ & $26 \cdot 5$ & $33.2 \ddagger$ \\
\hline LDL-cholesterol (mg/l) & 1295 & 1347 & $1322 \dagger$ & $1214 \ddagger$ \\
\hline \multicolumn{5}{|l|}{ TAG $(m g / l)$} \\
\hline Median & 1405 & 1280 & 1370 & 1405 \\
\hline Interquartile range & $960-2240$ & $920-1855$ & $1030-1820$ & $960-2240$ \\
\hline HDL-cholesterol (mg/l) & 509 & $478 \S$ & $541 \dagger$ & 507 \\
\hline Total cholesterol (mg/l) & 2120 & 2121 & $2172 \dagger$ & 2065 \\
\hline Glucose $(\mathrm{mg} / \mathrm{l})$ & 1067 & $1013 \S$ & $1068 \dagger$ & $1120 \ddagger$ \\
\hline Insulin ( $\mu \mathrm{IU} / \mathrm{ml})$ & $13 \cdot 5$ & $15 \cdot 2 \S$ & $10 \cdot 3 \dagger$ & $15 \cdot 1$ \\
\hline Diabetes (\%) & 7.5 & $3 \cdot 3$ & $6 \cdot 1 \dagger$ & $13.4 \ddagger$ \\
\hline Current smoker (\%) & $23 \cdot 5$ & $7 \cdot 2 \S$ & $49 \cdot 2 \dagger$ & $13 \cdot 1$ \\
\hline Alcohol drinker (\%) & $49 \cdot 6$ & $44 \cdot 1 \S$ & $67 \cdot 1 \dagger$ & $36 \cdot 9$ \\
\hline \multicolumn{5}{|l|}{$\mathrm{CRP}(\mathrm{mg} / \mathrm{l})$} \\
\hline Median & 0.6 & 1.0 & 0.3 & 0.7 \\
\hline Interquartile range & $0.3-1.3$ & $0.5-1.8$ & $0.2-0.7$ & $0.3-1.3$ \\
\hline \multicolumn{5}{|l|}{ PAl-1 (ng/ml) } \\
\hline Median & 37.4 & $27 \cdot 4 \S$ & $41 \cdot 2$ & $45 \cdot 9 \ddagger$ \\
\hline Interquartile range & $23 \cdot 3-58 \cdot 4$ & $15 \cdot 7-41 \cdot 3$ & $24 \cdot 3-67 \cdot 3$ & $31 \cdot 6-61 \cdot 7$ \\
\hline
\end{tabular}

CRP, C-reactive protein; PAI-1, plasminogen activator inhibitor-1.

* Significance test was based on ANOVA, followed by Bonferroni's test if the overall ANOVA was significant.

† Values were significantly different between Japanese and Japanese-American men as determined by Bonferroni's test $(P<0.01)$.

$\ddagger$ Values were significantly different between Caucasian and Japanese-American men as determined by Bonferroni's test $(P<0.01)$.

$\S$ Values were significantly different between Caucasian and Japanese men as determined by Bonferroni's test $(P<0 \cdot 01)$.

respectively. The correlation coefficient between LA and AA was $0.06(P=0.059)$.

Pooled and centre-specific analyses reveal that serum $n-6$ fatty acids were inversely associated with PAI-1 in the total population as well as in each of three different populations (Table 3). Pooled analyses showed that serum total $n-6$ fatty acids, LA and AA, had significant inverse associations with
PAI-1 levels, even after adjusting for covariates. In centrespecific analyses, PAI-1 had significant inverse associations with total $n$ - 6 fatty acids and LA over three study populations. These significant associations remained after multivariate adjustments. PAI-1 was inversely associated with AA. No significant interaction existed in the associations of serum $n-6$ fatty acids, LA and AA, with PAI- 1 according to the study

Table 2. Distribution of serum fatty acids $(\%)^{*}$

\begin{tabular}{|c|c|c|c|c|}
\hline & $\begin{array}{l}\text { Total } \\
(n 915)\end{array}$ & $\begin{array}{l}\text { Caucasian } \\
\text { men }(n 304)\end{array}$ & $\begin{array}{l}\text { Japanese } \\
\text { men }(n 313)\end{array}$ & $\begin{array}{c}\text { Japanese-American } \\
\text { men }(n \text { 298) }\end{array}$ \\
\hline PUFA & $45 \cdot 4$ & $45 \cdot 6 \dagger$ & 44.3‡ & $46 \cdot 5$ \\
\hline Total $n-6$ fatty acids $\S$ & 39.0 & $41.3 \dagger$ & $34.7 \ddagger$ & $41 \cdot 1$ \\
\hline Linoleic acid & $28 \cdot 8$ & $29.9 \dagger$ & $26 \cdot 5 \ddagger$ & $30 \cdot 0$ \\
\hline Arachidonic acid & $8 \cdot 1$ & $9.0 \dagger$ & $6 \cdot 6 \ddagger$ & 8.9 \\
\hline Total $n-3$ fatty acids $\|$ & 6.5 & $4.2 \dagger$ & $9 \cdot 6 \ddagger$ & 5.49 \\
\hline Marine $n-3$ fatty acids ${ }^{*}$ & $6 \cdot 0$ & $3.8 \dagger$ & $9 \cdot 3 \ddagger$ & 4.9 वी \\
\hline$\alpha$-Linolenic fatty acids & 0.3 & $0.3 \dagger$ & $0.2 \ddagger$ & $0.4 \pi$ \\
\hline MUFA†† & $20 \cdot 4$ & $20 \cdot 3 \dagger$ & $21 \cdot 2 \ddagger$ & $19 \cdot 6$ \\
\hline SFA & $31 \cdot 2$ & $30.9+$ & $31.7 \ddagger$ & 30.9 \\
\hline trans-Fatty acids ${ }^{\S \S}$ & 0.8 & $1.0 \dagger$ & $0.6 \ddagger$ & 0.99 \\
\hline
\end{tabular}

* Significance test was based on ANOVA followed by Bonferroni's test if the overall ANOVA was significant.

† Significant difference between Caucasian and Japanese men as determined by Bonferroni's test $(P<0.01)$.

$\ddagger$ Significant difference between Japanese and Japanese-American men as determined by Bonferroni's test $(P<0.01)$

$\S$ Total $n-6$ fatty acids indicate the sum of linoleic acid $(18: 2 n-6), \gamma$-linoleic acid $(18: 3 n-6)$, dihomo- $\gamma$-linolenic acid $(20: 3 n-6)$ and arachidonic acid $(20: 4 n-6)$.

\| Total $n-3$ fatty acids indicate marine-derived $n$-3 fatty acids, eicosatetraenoic acid $(20: 4 n-3)$ and $\alpha$-linolenic acid (22:18n-3).

I Significant difference between Caucasian and Japanese-American men as determined by Bonferroni's test $(P<0 \cdot 01)$.

** Marine-derived $n-3$ fatty acids were defined as EPA $(20: 5 n-3)$, docosapentaenoic acid $(22: 5 n-3)$ and DHA $(22: 6 n-3)$

t† MUFA indicate the sum of palmitoleic acid (16:1n-7), oleic acid $(18: 1 n-9)$ and cis-vaccenic acid (18:1n-7).

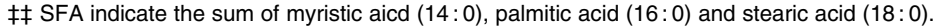

$\S \S$ trans-Fatty acids indicate the sum of palmitelaidic acid (16n-7:1t), trans-9-octadecanoic acid (18n-9:1t) and linolelaidic acid (18n-6:2tt). 
Table 3. Centre-specific and pooled associations between $n-6$ fatty acids and $\log (\mathrm{PAl}-1)$

\begin{tabular}{|c|c|c|c|c|}
\hline & \multicolumn{4}{|c|}{ Standardised parameter estimates } \\
\hline & $\begin{array}{l}\text { Total } \\
(n 915)\end{array}$ & $\begin{array}{l}\text { Caucasian } \\
\text { men }(n 304)\end{array}$ & $\begin{array}{c}\text { Japanese } \\
\text { men }(n 313)\end{array}$ & $\begin{array}{c}\text { Japanese-American } \\
\text { men ( } n \text { 298) }\end{array}$ \\
\hline \multicolumn{5}{|c|}{ Total $n-6$ fatty acids $\dagger$} \\
\hline Univariate & $-0.27^{\star}$ & $-0.32^{*}$ & $-0.25^{\star}$ & $-0.27^{\star}$ \\
\hline Model I‡ & $-0.32^{\star}$ & $-0.32^{*}$ & $-0.24^{*}$ & $-0.27^{\star}$ \\
\hline Model II§ & $-0.24^{\star}$ & $-0 \cdot 18^{\star}$ & $-0.20^{\star}$ & $-0.21^{\star}$ \\
\hline Model IIII| & $-0 \cdot 13^{*}$ & $-0.06^{\star}$ & $-0 \cdot 12^{\star}$ & $-0 \cdot 10^{\star}$ \\
\hline Model IVף & $-0.14^{\star}$ & $-0.09^{\star}$ & $-0.12^{\star}$ & $-0.09^{\star}$ \\
\hline \multicolumn{5}{|l|}{ Linoleic acid } \\
\hline Univariate & $-0.23^{\star}$ & $-0.29^{*}$ & $-0.20^{\star \star}$ & $-0.23^{*}$ \\
\hline Model I† & $-0.24^{\star}$ & $-0.29^{\star}$ & $-0 \cdot 19^{\star \star}$ & $-0.23^{\star}$ \\
\hline Model II§ & $-0.17^{\star}$ & $-0.15^{\star}$ & $-0 \cdot 15^{\star}$ & $-0.18^{*}$ \\
\hline Model IIII| & $-0 \cdot 10^{\star}$ & $-0.07^{\star}$ & $-0.07^{\star}$ & $-0 \cdot 12^{\star}$ \\
\hline Model IV & $-0 \cdot 10^{\star}$ & $-0.08^{\star}$ & $-0.04^{\star}$ & $-0.11^{*}$ \\
\hline \multicolumn{5}{|c|}{ Arachidonic acid } \\
\hline Univariate & $-0 \cdot 16^{*}$ & $-0 \cdot 13^{\star \star \star}$ & $-0 \cdot 19^{\star \star}$ & -0.11 \\
\hline Model $\ddagger$ & $-0.14^{*}$ & -0.13 & $-0 \cdot 18^{\star \star}$ & -0.11 \\
\hline Model II§ & $-0 \cdot 10^{\star}$ & $-0.08^{\star}$ & $-0.17^{\star}$ & $-0.07^{\star}$ \\
\hline Model IIIII & $-0.01^{\star}$ & $-0.003^{\star}$ & $-0 \cdot 10^{\star}$ & $0.04^{\star}$ \\
\hline Model IVף & $-0.01^{*}$ & $-0.003^{*}$ & $-0 \cdot 10^{*}$ & $0.04^{*}$ \\
\hline
\end{tabular}

CRP, C-reactive protein.

Marine-derived $n-3$ fatty acids were defined as EPA $(20: 5 n-3)$, docosapentaenoic acid $(22: 5 n-3)$ and DHA (22:6n-3). Total $n$-3 fatty acids indicate marine-derived $n$-3 fatty acids, eicosatetraenoic acid $(20: 4 n-3)$ and $\alpha$-linolenic acid $(22: 18 n-3)$. trans-Fatty acids indicate the sum of palmitelaidic acid (16n-7: 1t), trans-9-octadecanoic acid (18n-9: 1t) and linolelaidic acid (18n-6:2tt).

Values were significantly different: ${ }^{\star} P<0.001 ;{ }^{\star \star} P<0.01 ;{ }^{\star \star \star} P<0.05$.

$\dagger$ Total $n-6$ fatty acids indicate the sum of linoleic acid $(18: 2 n-6), \gamma$-linoleic acid $(18: 3 n-6)$, dihomo- $\gamma$-linolenic acid $(20: 3 n-6)$ and arachidonic acid $(20: 4 n-6)$.

$\ddagger$ Adjusted for age.

$\S$ Additionally adjusted for BMI, current smoking, alcohol drinking, hypertension and diabetes.

I| Further adjusted for LDL-cholesterol, HDL-cholesterol, TAG and CRP.

I Continuously adjusted for marine $n-3$ fatty acids and trans-fatty acids.

centres $(P=0.09,0.08$ and $0 \cdot 24$, respectively). Standard parameter estimates indicate a standard deviation unit change in log-transformed PAI- 1 per $1 \mathrm{SD}$ unit increase in serum $n-6$ fatty acids.

\section{Discussion}

The present population-based cross-sectional study found that total serum $n-6$ fatty acids were inversely and significantly associated with PAI-1 among 915 men, aged 40-49 years. Additionally, both LA and AA showed significant inverse associations with PAI-1 levels $(P<0 \cdot 0001)$.

The present study may provide a novel mechanism on the cardioprotective benefits of $n-6$ fatty acids by improving the fibrinolytic response, such as reducing PAI-1. The present finding of an inverse association between serum n- 6 fatty acids and PAI-1 is consistent with the results of several previous studies $^{(24,25)}$, but not all ${ }^{(26)}$. These findings of $n-6$ fatty acids suggest a favourable fibrinolytic response on vascular thrombosis, including a decrease in platelet aggregation. Fleischman et al. ${ }^{(24)}$ found an increased platelet aggregation time $(P<0.05)$ and a decreased disaggregation time $(P<0.01)$ on a dietary LA in each participant for 2 weeks from about $2.9 \%$ to about $5.0 \%$ of energy among sixty-six subjects. A cross-over study by Thijssen et al. ${ }^{(27)}$ also demonstrated an increased platelet aggregation time while on a LA diet in comparison with a SFA diet in eighteen men $(P=0 \cdot 04)$. O'Brien et al. ${ }^{(25)}$ conducted a clinical trial in thirty-nine healthy men for 6 weeks with either a PUFA diet (sunflower oil-based foods, 65\% LA) replaced for saturated fat or a normal diet. They found decreased platelet count $(P=0.01)$ and increased bleed time $(P=0.05)^{(25)}$. Furthermore, previous studies, including the Nurses' Health Study ${ }^{(5)}$, have suggested that $n-6$ fatty acids lower the CHD risk, through a decrease in blood pressure ${ }^{(8)}$, a reduction in thrombosis $^{(9)}$ and an improvement in insulin sensitivity ${ }^{(10)}$.

The present results of the inverse association between serum n-6 fatty acids and PAI- 1 are partially inconsistent with the results of a previous study. Byberg et al. ${ }^{(26)}$ showed that PAI-1 activity has a significant inverse association with serum LA but a significant positive association with serum AA in their sub-analysis with 381 men from a populationbased cross-sectional sample of 871 men aged 70 years. The discrepancy in the association of PAI- 1 with AA may be attributed to different measurements of PAI- 1 and fatty acids or to different ages of participants. In the measurements of PAI-1 and fatty acids, Byberg et al. measured PAI-1 activity (i.e. a free active form) and serum cholesteryl esters for fatty acid measurements in older participants (mean average 70 years), whereas we measured total plasma PAI-1 levels (i.e. free active, free latent and complex with tissue plasminogen activator forms) and fatty acids in serum cholesteryl esters, phospholipids and TAG, in middle-aged men (aged 40-49 years). Although the previous study demonstrated a linear association between PAI-1 activity and PAI-1 antigen ( $r$ 0.80 in platelet-poor plasma; $r 0.88$ in platelet-rich plasma), about 
$66.7 \%$ of PAI-1 antigen in plasma was active ${ }^{(22)}$. Considering the very short half-life of PAI-1 levels and various processes (e.g. temperature, time or $\mathrm{pH}$ ) for handling the blood samples as well as significant diurnal change in PAI-1, the PAI-1 antigen measurement as in the present study may have the advantage of detecting comprehensive forms of relatively unstable total plasma PAI-1, rather than measuring only an active form.

Future studies are required in order to elucidate possible reasons of the discrepancy between the in vitro and population studies. Several in vitro studies have shown that LA increases the secretion of PAI-1 in HepG2 cells ${ }^{(28,29)}$. In vitro studies have reported that AA-produced eicosanoids promoted neutrophil adhesion ${ }^{(30)}$ and IL-1 $\beta$ production by human monocytes ${ }^{(31)}$. However, more recent studies have demonstrated no effect or a beneficial effect. A double-blind placebo-controlled study with an AA supplementation of $840 \mathrm{mg} / \mathrm{d}$ for 4 weeks demonstrated no effect on platelet aggregation in twenty-four healthy Japanese men who had relatively high levels of fish oil consumption ${ }^{(32)}$. In another clinical trial of ten healthy men taking a $200 v$. $1500 \mathrm{mg} / \mathrm{d}$ AA regimen, Nelson et al. ${ }^{(33)}$ found borderline significance between higher AA intake and prolonged bleeding time $(P=0 \cdot 06)$. Although several AA-derived eicosanoids may indeed have a pro-inflammatory role, recent studies have suggested that several AA-derived eicosanoids may play an anti-inflammatory role ${ }^{(34)}$.

Mechanisms responsible for the association of $n-6$ fatty acids with PAI-1 require future studies. However, two possibilities exist. First, $n-6$ fatty acids may delay platelet aggregation so that PAI-1, acting as an acute-phase reactant, is decreased within the haemodynamic balance and thrombotic response, during vascular injury, in atherosclerosis and CHD. Several previous studies have shown that LA reduces platelet aggregation $^{(24,25)}$. Second, LA may reduce PAI-1 levels through its cholesterol-lowering effect. A previous study from ERAJUMP found that higher levels of serum LA and AA were associated with lower levels of LDL and $\mathrm{VLDL}^{(35)}$. An in vitro study showed that VLDL led to increased PAI-1 ${ }^{(36)}$. These reduced cholesterol levels may improve or modulate the fibrinolytic response.

We additionally examined the associations of other fatty acids with PAI- 1 . Serum marine $n-3$ fatty acids over the three populations showed little overlapped distributions and the lack of consistent associations (see Table S1 of the supplementary material, available online http://www.journals.cambridge. org/bjn). trans-Fatty acids of three populations were positively associated with PAI-1 (see Table S2 of the supplementary material, available online http://www.journals.cambridge. org/bjn).

The strengths of the present study include the following: (1) the association was examined in a randomly selected population-based sample and (2) the sample size was relatively large. However, the present study also has several limitations: (1) the cross-sectional study design could not assess causality; (2) the study population included only men aged 40-49 years, which may limit the generalisability to other populations and (3) as an observational study, the present study may include residual confounding or potentially unmeasured factors, such as total energy intake ${ }^{(37)}$.

In conclusion, serum $n-6$ fatty acids were inversely and significantly associated with PAI-1 levels in a populationbased cross-sectional study. Total $n-6$ fatty acids, especially LA and AA, were inversely and significantly associated with PAI-1 levels in both univariate and multivariate models. These findings suggest that $n-6$ fatty acids may have favourable effects on fibrinolysis. A future study to examine the causality between $n-6$ fatty acid and PAI- 1 is warranted.

\section{Acknowledgements}

The present study was funded by the National Institutes of Health R01 HL68200 and HL071561 and from the Japanese Ministry of Education, Culture, Sports, Science and Technology, B 16790335 and A 13307016. The authors disclose that there are no conflicts of interest. S. L. wrote the first manuscript. J. D. C., T. K., R. W. E., T. T., A. E.-S., S. K., T. S., D. E., H. U., L. H. K. and A. S. collected the data. S. L., T. O. and A. S. analysed the data. S. L., R. W. E., K. M., C. S., J. C., A. F., T. O., H. U., L. H. K. and A. S. interpreted the data. J. D. C., R. W. E., K. M., J. C., T. S., K. M., D. E., L. H. K. and A. S. gave critical comments. S. L. with A. S. revised the manuscript.

\section{References}

1. Ha H, Oh EY \& Lee HB (2009) The role of plasminogen activator inhibitor 1 in renal and cardiovascular diseases. Nat Rev Nephrol 5, 203-211.

2. Senno SL \& Pechet L (1999) Clinical implications of elevated PAI-1 revisited: multiple arterial thrombosis in a patient with essential thrombocythemia and elevated plasminogen activator inhibitor-1 (PAI-1) levels: a case report and review of the literature. J Thromb Thrombolysis 8, 105-112.

3. Folsom AR, Aleksic N, Park E, et al. (2001) Prospective study of fibrinolytic factors and incident coronary heart disease: the Atherosclerosis Risk in Communities (ARIC) Study. Arterioscler Thromb Vasc Biol 1, 611-617.

4. Thogersen AM, Jansson JH, Boman K, et al. (1998) High plasminogen activator inhibitor and tissue plasminogen activator levels in plasma precede a first acute myocardial infarction in both men and women: evidence for the fibrinolytic system as an independent primary risk factor. Circulation 98, 2241-2247.

5. Oh K, Hu FB, Manson JE, et al. (2005) Dietary fat intake and risk of coronary heart disease in women: 20 years of follow-up of the nurses' health study. Am J Epidemiol $16 \mathbf{1}$ 672-679.

6. Harris WS, Poston WC \& Haddock CK (2007) Tissue $n-3$ and $n-6$ fatty acids and risk for coronary heart disease events. Atherosclerosis 193, 1-10.

7. Laaksonen DE, Nyyssonen K, Niskanen L, et al. (2005) Prediction of cardiovascular mortality in middle-aged men by dietary and serum linoleic and polyunsaturated fatty acids. Arch Intern Med 165, 193-199.

8. Zhao WS, Zhai JJ, Wang YH, et al. (2009) Conjugated linoleic acid supplementation enhances antihypertensive effect of ramipril in Chinese patients with obesity-related hypertension. Am J Hypertens 22, 680-686. 
9. Knapp HR (1997) Dietary fatty acids in human thrombosis and hemostasis. Am J Clin Nutr 65, Suppl. 5, 1687-1698S.

10. Laaksonen DE, Lakka TA, Lakka HM, et al. (2002) Serum fatty acid composition predicts development of impaired fasting glycaemia and diabetes in middle-aged men. Diabet Med 19, 456-464.

11. Calder PC (2009) Polyunsaturated fatty acids and inflammatory processes: new twists in an old tale. Biochimie $\mathbf{9 1}$, 791-795.

12. Nelson GJ, Kelley DS, Emken EA, et al. (1997) A human dietary arachidonic acid supplementation study conducted in a metabolic research unit: rationale and design. Lipids 32, 415-420.

13. Harris WS, Mozaffarian D, Rimm E, et al. (2009) Omega-6 fatty acids and risk for cardiovascular disease: a science advisory from the American Heart Association Nutrition Subcommittee of the Council on Nutrition, Physical Activity, and Metabolism; Council on Cardiovascular Nursing; and Council on Epidemiology and Prevention. Circulation 119, 902-907.

14. Willett WC (2007) The role of dietary $n$ - 6 fatty acids in the prevention of cardiovascular disease. J Cardiovasc Med (Hagerstown) 8, Suppl. 1, S42-S45.

15. Kohler HP \& Grant PJ (2000) Plasminogen-activator inhibitor type 1 and coronary artery disease. $N$ Engl J Med 342, 1792-1801.

16. Levenson J, Giral P, Razavian M, et al. (1995) Fibrinogen and silent atherosclerosis in subjects with cardiovascular risk factors. Arterioscler Thromb Vasc Biol 15, 1263-1268.

17. Sekikawa A, Ueshima H, Kadowaki T, et al. (2007) Less subclinical atherosclerosis in Japanese men in Japan than in White men in the United States in the post-World War II birth cohort. Am J Epidemiol 165, 617-624.

18. Kagan A (1996) The Honolulu Heart Program: an Epidemiological Study of Coronary Heart Disease and Stroke. New York: Harwood Academic Press.

19. Abbott RD, Ueshima H, Rodriguez BL, et al. (2007) Coronary artery calcification in Japanese men in Japan and Hawaii. Am J Epidemiol 166, 1280-1287.

20. Declerck PJ \& Collen D (1990) Measurement of plasminogen activator inhibitor 1 (PAI-1) in plasma with various monoclonal antibody-based enzyme-linked immunosorbent assays. Thromb Res Suppl 10, 3-9.

21. Macy EM, Meilahn EN, Declerck PJ, et al. (1993) Sample preparation for plasma measurement of plasminogen activator inhibitor-1 antigen in large population studies. Arch Pathol Lab Med 117, 67-70.

22. Declerck PJ, Alessi MC, Verstreken M, et al. (1988) Measurement of plasminogen activator inhibitor 1 in biologic fluids with a murine monoclonal antibody-based enzyme-linked immunosorbent assay. Blood 71, 220-225.

23. Sekikawa A, Curb JD, Ueshima H, et al. (2008) Marinederived $n-3$ fatty acids and atherosclerosis in Japanese,
Japanese-American, and white men: a cross-sectional study. J Am Coll Cardiol 52, 417-424.

24. Fleischman AI, Justice D, Bierenbaum ML, et al. (1975) Beneficial effect of increased dietary linoleate upon in vivo platelet function in man. J Nutr 105, 1286-1290.

25. O'Brien JR, Etherington MD \& Jamieson S (1976) Effect of a diet of polyunsaturated fats on some platelet-function tests. Lancet 2, 995-996.

26. Byberg L, Smedman A, Vessby B, et al. (2001) Plasminogen activator inhibitor-1 and relations to fatty acid composition in the diet and in serum cholesterol esters. Arterioscler Thromb Vasc Biol 21, 2086-2092.

27. Thijssen MA, Hornstra G \& Mensink RP (2005) Stearic, oleic, and linoleic acids have comparable effects on markers of thrombotic tendency in healthy human subjects. $J$ Nutr 135, 2805-2811.

28. Banfi C, Rise P, Mussoni L, et al. (1997) Linoleic acid enhances the secretion of plasminogen activator inhibitor type 1 by HepG2 cells. J Lipid Res 38, 860-869.

29. Ye P, He YL, Wang Q, et al. (2007) The alteration of plasminogen activator inhibitor-1 expression by linoleic acid and fenofibrate in HepG2 cells. Blood Coagul Fibrinolysis 18, $15-19$.

30. Bates EJ, Ferrante A, Smithers L, et al. (1995) Effect of fatty acid structure on neutrophil adhesion, degranulation and damage to endothelial cells. Atherosclerosis 116, 247-259.

31. Sinha B, Stoll D, Weber PC, et al. (1991) Polyunsaturated fatty acids modulate synthesis of TNF-[alpha] and interleukin-1[beta] by human MNC in vitro. Cytokine 3, 457-457.

32. Kusumoto A, Ishikura Y, Kawashima H, et al. (2007) Effects of arachidonate-enriched triacylglycerol supplementation on serum fatty acids and platelet aggregation in healthy male subjects with a fish diet. Br J Nutr 8, 626-635.

33. Nelson GJ, Schmidt PC, Bartolini G, et al. (1997) The effect of dietary arachidonic acid on platelet function, platelet fatty acid composition, and blood coagulation in humans. Lipids 2, 421-425.

34. Schmitz G \& Ecker J (2008) The opposing effects of $n-3$ and n-6 fatty acids. Prog Lipid Res 7, 147-155.

35. Choo J, Ueshima H, Curb JD, et al. (2010) Serum n-6 fatty acids and lipoprotein subclasses in middle-aged men: the population-based cross-sectional ERA-JUMP study. Am J Clin Nutr 1, 1195-1203.

36. Nilsson L, Gafvels M, Musakka L, et al. (1999) VLDL activation of plasminogen activator inhibitor-1 (PAI-1) expression: involvement of the VLDL receptor. $J$ Lipid Res 40, 913-919.

37. Willett WC, Howe GR \& Kushi LH (1997) Adjustment for total energy intake in epidemiologic studies. Am J Clin Nutr $\mathbf{6 5}$, 1220 S-11228. 